\title{
Influence of Symbiotic Interaction between Fungus, Virus, and Tomato Plant in Combating Drought Stress
}

\author{
Safaa Al-Hamdani ${ }^{*}$, Austen Stoelting ${ }^{1}$, Mustafa Morsy ${ }^{2}$ \\ ${ }^{1}$ Department of Biology, Jacksonville State University, Jacksonville, USA \\ ${ }^{2}$ Department of Biology, University of West Alabama, Livingston, USA \\ Email: sah@jsu.edu
}

Received 16 April 2015; accepted 27 June 2015; published 30 June 2015

Copyright (C) 2015 by authors and Scientific Research Publishing Inc.

This work is licensed under the Creative Commons Attribution International License (CC BY). http://creativecommons.org/licenses/by/4.0/

(c) (i) Open Access

\section{Abstract}

The influence of the three-way interaction between the fungus (Curvularia protuberata), virus (CThTV), and tomato (Solanum lycopersicum) in combating drought stress was evaluated in this study. The plants in this greenhouse experiment were grown under conditions of $400 \pm 150$ $\mu \mathrm{mol} \cdot \mathrm{m}^{-2} \cdot \mathrm{s}^{-1}$ photon flux density, $45 \%$ to $50 \%$ relative humidity (RH), and $30^{\circ} \mathrm{C} \pm 2^{\circ} \mathrm{C}$. Tomato seeds were germinated and inoculated with the combination of the fungus and virus at the seedling stage. The plants were allowed to grow for two weeks and randomly selected individuals were utilized. The selected plants were grown in one gallon pots containing organic potting soil. The treatments included non-symbiotic (NS), virus-free (VF), and symbiotic (An) plants. Each treatment received twelve samples and each sample was allowed to grow for an additional two weeks under drought stress. At that time, plants were exhibiting drought stress symptoms including visible wilting. Six samples from each treatment were utilized in determining selected physiological responses of tomato at pre-anthesis stage. The remaining six samples from each treatment were re-watered once and allowed to grow until they reached the anthesis stage. When they showed visible signs of wilting, the same physiological responses measured during pre-anthesis were conducted. The samples of each treatment were utilized at the end of each stage in determining photosynthetic rate, stomata conductance, photosynthetic pigments, water potential, and soluble sugar content. Plant growth, chlorophyll $a$, chlorophyll $b$, photosynthetic rate, stomata conductance, water potential, and soluble sugar content were similarly affected by the various treatments. However, carotenoids were significantly higher at pre-anthesis in the symbiotic plants in comparison to other treatments. Additionally, photosynthesis appeared to be significantly higher at anthesis compared to pre-anthesis for all treatments.

\footnotetext{
"Corresponding author.
} 


\section{Keywords}

\section{Tomato Plant, Curvularia protuberate, Virus (CThTV), Drought Stress}

\section{Introduction}

Fossil records show that fungal symbionts existed in plants over 400 million years ago [1] and may have been a key component in the shift from aquatic to terrestrial plants [2]. The relationship between plants and soil microorganisms has recently received more attention due to the fact that many microorganisms out of the approximately 30,000 species existing in soil at any given time demonstrate the potential of benefiting plants. Many scientific studies have examined the importance of plant-fungal symbiotic relationships in enhancing plant tolerance for various abiotic stresses such as drought, salinity, heat, cold, oxidative stress, and metal toxicity [3][7]. With the continuous dramatic climate changes such as global warming and widespread drought in many regions, serious problems in food production are predicted with increases in demand as a result of the increase in human population [8]. It has been reported that 868 million people on Earth (12\% of the population) were undernourished between 2010 and 2012 [9]. It has become imperative to improve food production to keep pace with the increasing demand. The use of beneficial microorganisms to extend the growing range of crop plants is a feasible technique to increase food production.

Endophytes and mycorrhizae are two major classes of fungal symbionts associated with internal plant tissues [10]. Endophytes are found in all plant tissues including roots, stems, leaves, or flowers, whereas mycorrhizal fungi are only found in roots and the extending rhizosphere. Endophytes are the largest group of fungal symbionts, spanning a large host range from both monocot and eudicot plants [6]. Endophytes are further classified into four different classes based on host range, tissue colonization, biodiversity levels, transmission between host generations, and acquired fitness benefits [11]. Class 1 endophytes are known as clavicipitaceousendophytes (C-endophytes), and classes 2, 3, and 4 are nonclavicipitaceousendophytes (NC-endophytes). NC-endophytes are a highly diverse group consisting of many undescribed species and largely unknown ecological roles.

The fungus Curvularia protuberata Nelson is classified within Class 2 of the NC-endophytes. This class is distinguished from the other classes in that it can colonize shoots and roots and bestow adaptation advantages to host plants growing under a wide range of abiotic and biotic stresses (Rodriguez et al., 2009). This particular fungus has been mutually associated with panic grass (Dichanthelium lanuginosum (Elliot) Gould), but also with other hosts such as tomato (Solanum lycopersicum L.) [12] reported that C. protuberata inoculated in panic grass and tomato failed to induce heat tolerance without the presence of Curvularia thermal tolerance virus (CThTV). They suggested that the induced tolerance resulting from the symbiotic interaction involved osmoprotection due to significant accumulation of trehalose, glycine, betaine, and taurine. Rodriguez et al. (2008) reported that plants activated a number of physiological responses under water stress, and fungal endophytes were known to aid in these responses by promoting drought stress tolerance. Osmotic adjustment and water use efficiency were among the major responses associated with enhanced tolerance in this work [6]. Furthermore, they reported that tomato plant water consumption was 30\% - 50\% less in symbiotic plants with a Class 2 endophyte in comparison to non-symbiotic plants. They concluded that water use efficiency may be considered more significant than osmotic regulation in combating drought stress. A wide range of metabolic solutes serve as protectants and deterrents of osmotic stress [4]. Some sugars and sugar alcohols are known to protect plant cells from damage by either scavenging reactive oxygen species (ROS) or stabilizing protein structures [13]. One of the major soluble sugars influencing drought stress is trehalose [3] [13]. Trehalose is a non-reducing disaccharide found in bacteria, fungi, and some desiccation-tolerant plants, where it can serve as an osmoprotectant and storage carbohydrate during stress conditions such as drought and increased salinity [13]. The effectiveness of trehalose is mostly the result of stabilizing the cell membrane by establishing hydrogen bonds with the polar head, thereby altering the space of the polar head [14]. An improvement of water stress status in tomato due to osmotic adjustment was also reported as a result of an arbuscular mycorrhizal fungal symbiotic interaction [15].

The three-way symbiotic relationship described with tomato, C. protuberata, and CThTV has been demonstrated as a beneficial relationship in combating stresses such as high temperature stress [5] [7]. However, the impact of such relationship on drought, specifically on cash crops such as tomato, has yet to be established. The 
objective of this study was to determine the impact of this three-way symbiotic relationship on tomato plants under drought stress. It was expected that soluble sugar concentration and drought stress tolerance would be greatest in treatments where the three-way symbiotic relationship was established. Selected physiological responses including photosynthetic rate, stomata conductance, photosynthetic pigments, and leaf water potential were evaluated to determine the impact of the three-way relationship. Additionally, the role of soluble sugars in enhancing drought tolerance was evaluated. These physiological parameters were determined at the pre-anthesis and anthesis stages in an attempt to examine the different possible responses as influenced by the stage of growth and development.

\section{Materials and Methods}

\subsection{Plant Material}

To accomplish the objectives of this study, tomato plants (cultivar "Rutgers") were established from seeds. The seeds were acquired from Tomato Grower’s Supply (catalog number \#4050) and germinated in small plastic trays containing commercial potting soil. The seedlings were allowed to grow under greenhouse conditions to approximately $10 \mathrm{~cm}$. To inoculate the individual seedlings with $C$. protuberate and CThTV, the procedure outlined by Morsy et al. [7] was followed. The individual seedlings were removed from the soil and washed thoroughly with autoclaved water to remove debris. Seedlings were then placed in a $50 \mathrm{~mL}$ beaker filled with autoclaved $0.035 \%$ agarose solution containing fungal spores contaminated with CThTV. The seedlings were allowed to remain in the contaminated beakers for two days under light conditions. This procedure was repeated with spores uncontaminated with the virus to ensure virus free fungus. Next, the seedlings were transplanted into small plastic trays containing autoclaved potting soil and allowed to grow for an additional 10 days. The individual plants were then transplanted into one gallon pots containing autoclaved, organic potting soil. The soil $\mathrm{pH}$ was 5.6 and concentrations of nitrogen, phosphorus, and potassium were 179, 21, and 200 ppm, respectively. Plants without fungus and virus are referred to as non-symbiotic (NS) plants, plants inoculated with only the fungus but not the virus are referred to as virus-free (VF) plants, and the symbiotic plants inoculated with both the fungus and the virus are labeled as anastomosis (An) plants, which refers to the hyphal fusion of the fungus. Twelve replicates (samples) were prepared for each treatment. The plants were allowed to grow for approximately two weeks under greenhouse conditions prior to drought treatment. To achieve the status of water stress, plants no longer received water until visible wilting was observed. Six randomly selected plants from each treatment were utilized to determine the physiological responses of water stress during the pre-anthesis stage. The remaining six samples from each treatment were re-watered once and allowed to grow until they reached the anthesis stage. When they showed visible signs of wilting, the same physiological responses measured during pre-anthesis were conducted.

\subsection{Growth Determination}

Six samples from each treatment were utilized to determine growth. Shoots and roots were separated and dried at $70^{\circ} \mathrm{C}$ for $48 \mathrm{~h}$. Individual samples were weighed and recorded.

\subsection{Gas Exchange Measurements}

Simultaneous measurements of $\mathrm{CO}_{2}$ assimilation and stomata conductance were taken from each of the six samples of each treatment using a Li-Cor 6200 portable photosynthesis system (Lincoln, NE, USA). Measurements were taken $6 \mathrm{~h}$ after the onset of the light period utilizing the second-most fully expanded leaf near the apical meristem. The leaf was enclosed in a flow-through Plexiglas assimilation chamber $(4.5 \times 11.8 \times 7.3 \mathrm{~cm})$ as described by McDermitt [16]. The measurement conditions were $400 \mu \mathrm{mol} \cdot \mathrm{m}^{-2} \cdot \mathrm{s}^{-1}$ photon flux density, $45 \%$ to $50 \%$ relative humidity $(\mathrm{RH})$, and $27^{\circ} \mathrm{C}$.

\subsection{Photosynthetic Pigment Determination}

Chlorophyll $a$, chlorophyll $b$, and carotenoids were measured from the same leaf that was earlier used for gas exchange measurements. Four leaf diskettes with a total area of $0.785 \mathrm{~cm}^{2}$ were taken from each of the six samples of each treatment. Leaf diskettes were placed in vials and incubated in $5 \mathrm{ml}$ of $\mathrm{N}, \mathrm{N}$-Dimethylformamide 
(DMF) solution. Individual vials were wrapped with aluminum foil and placed in the refrigerator at $4^{\circ} \mathrm{C}$ for $48 \mathrm{~h}$. Chlorophylls $a$ and $b$ were determined spectrophotometrically at wavelengths of 647 and $664.5 \mathrm{~nm}$ as described by Inskeep and Bloom (1985). The DMF extracts were further utilized to spectrophotometrically determine the carotenoid concentration at a wavelength of $470 \mathrm{~nm}$, and the concentration was calculated following the formula reported by Doong [17].

\subsection{Water Potential Measurement}

Leaf water potential was determined from each of the samples of each treatment following the procedure outlined by Al-Hamdani [18]. Randomly selected leaves from individual plants were homogenized using a mortar and pestle. A $100 \mu \mathrm{L}$ aliquot of cell sap was loaded on a paper disc and placed in a vapor pressure osmometer (model 5520, Wescor, Logan, UT).

\subsection{Soluble Sugar Analysis}

Root total soluble sugar content was analyzed following a modified procedure of Chatterton [19]. Freeze-dried root samples were ground through a $1 \mathrm{~mm}$ screen and $300 \mathrm{mg}$ in the first run and $150 \mathrm{mg}$ in the second run were weighed from each of the six samples of each treatment. Each aliquot was placed in a test tube with $5 \mathrm{ml}$ of $95 \%$ (v/v) ethanol and wrapped with aluminum foil. Test tubes were placed in a dry bath incubator at $80^{\circ} \mathrm{C}$ for $20 \mathrm{~min}$. The solution was allowed to settle and the supernatant was placed in a separately labeled test tube. An additional $5 \mathrm{ml}$ of $95 \%(\mathrm{v} / \mathrm{v})$ ethanol was added to the precipitate and a glass stirring rod was used to re-suspend the contents. The test tubes were placed in the dry bath incubator for an additional $20 \mathrm{~min}$. Again, the supernatant was extracted and combined with the first supernatant extraction to be used for the total sugars assay.

The colorimetric method for sugar determination reported by Dubois [20] was followed. Standards of 0, 130, 150, 200, 250, 300, and $350 \mathrm{mg} / \mathrm{ml}$ were prepared. A $0.15 \mathrm{ml}$ aliquot from each of the combined ethanol extraction samples was mixed with $0.5 \mathrm{ml}$ of $5 \%$ phenol in a $10 \mathrm{ml}$ test tube. The sample was vortexed for approximately 10 seconds before the addition of $2.5 \mathrm{ml}$ of $\mathrm{H}_{2} \mathrm{SO}_{4}$. The sample was vortexed an additional 10 seconds and left to cool to room temperature before being read on a spectrophotometer at $490 \mathrm{~nm}$. Using the standard curve, total soluble sugar content was calculated for each sample.

\subsection{Statistical Analysis}

This experiment was carried out as a completely randomized design (CRD). The experiment was repeated twice and the combined data from both experiments were analyzed using ANOVA as a complete randomized block design (CRBD). This was done to reduce experimental error resulting from the different times of carrying the experiment. Mean separations for the values that showed significant $F$ values $(P=0.05)$ of the ANOVA analyses were based on the least significant difference (LSD) test.

\section{Results and Discussion}

The symbiotic interaction between the tomato plants, CThTV, and the fungus (Curvularia protuberata) had no significant impact on the growth of the shoots and roots during pre-anthesis and anthesis (Figure 1). Generally, the plants showed significantly higher shoot growth than the roots at both stages. The influence of the symbiotic interaction between the tomato plant and fungus is highly dependent on the fungus species. Subramanian [15] reported that the arbuscularmycorrhizal fungus Glomus intraradices N.C. Schenck \& G. S. Sm. induced a significant increase in shoot growth, number of flowers, and fruit production of tomato plants growing under drought stress. Curvularia protuberata was reported by Rodriguez et al. (2008) to have a wide range of host monocot and eudicot plants. They reported that the fungus conferred drought tolerance in dunegrass (Leymusmollis (Trin.) Pilg., panic grass, rice (Oryza sativa L.), and tomato plants. The stress tolerance was attributed to a decrease in water consumption or enhanced tolerance to free radical damage, but not to osmoregulation. However, osmoregulation appears to be an important factor in enhancing other abiotic stresses such as heat through the significant production of a soluble sugar, trehalose [21] [22]. The total soluble sugar content, which includes trehalose, was found to be the same in all three treatments at both pre-anthesis and anthesis stages (Figure 2). Therefore, the osmotic adjustment of the tomato plants was the same at all three treatments. This was supported by the leaf water potential values at both pre- and anthesis stages, which showed no significant difference 


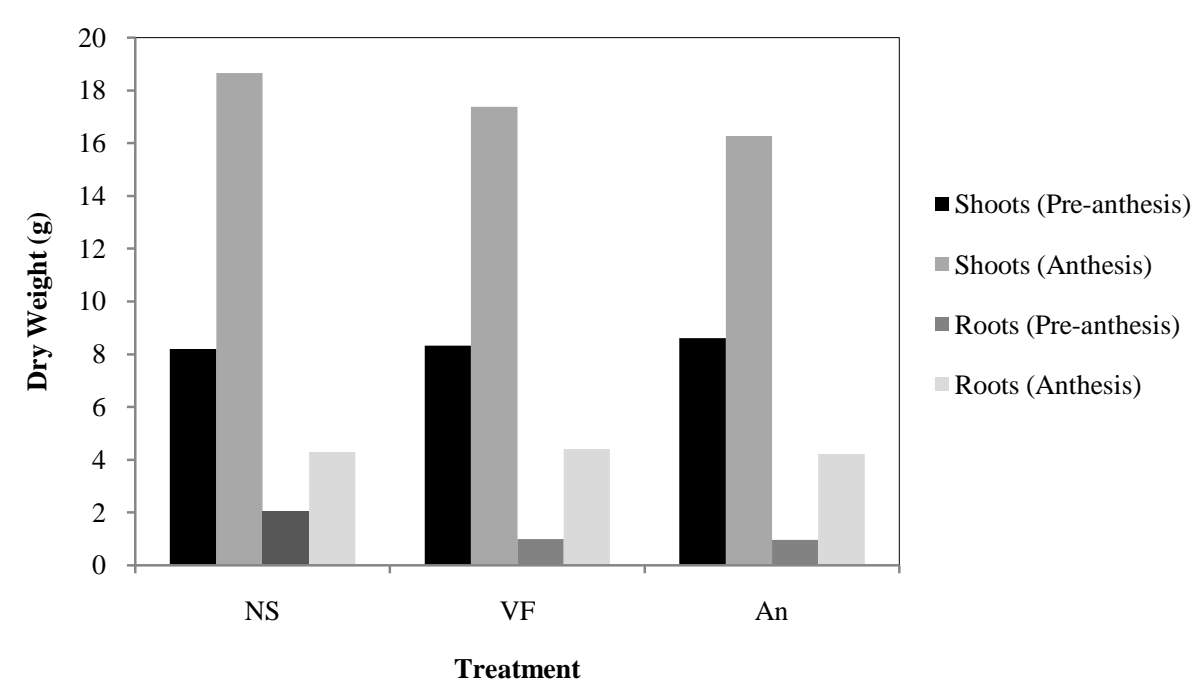

Figure 1. Effect of drought on shoot and root growth in tomato plants with selected fungus and virus interaction. There was no significant difference between the treatments based on the LSD test $(\mathrm{P}=0.05) .{ }^{*} \mathrm{NS}=$ non-symbiotic; $\mathrm{VF}=$ virus-free; $\mathrm{An}=$ anastomosis.

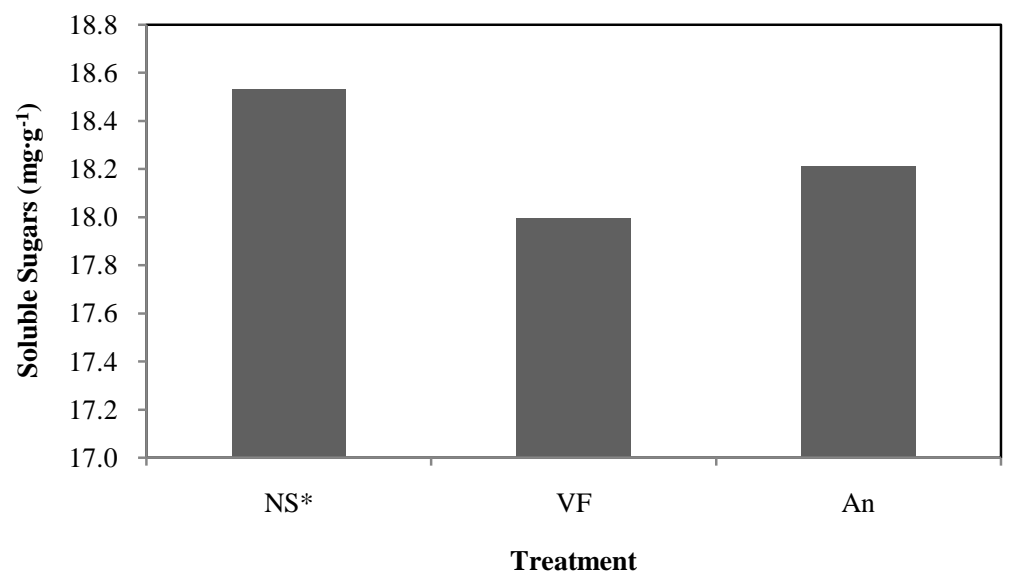

Figure 2. Effect of drought on soluble sugar content in tomato plants with selected fungus and virus interaction. There was no significant difference between the treatments based on the LSD test $(\mathrm{P}=0.05) .{ }^{*} \mathrm{NS}=$ non-symbiotic; $\mathrm{VF}=$ virus-free; $\mathrm{An}=$ anastomosis.

between the treatments (Table 1). Symbiotic association with mycorrhizae colonized by Glomus intraradices enhanced tomato growth and leaf water content primarily due to modified osmotic adjustment as a result of higher uptake of $\mathrm{N}$ and $\mathrm{P}$ [15]. This again demonstrated the differences among the fungi and their influence on the host plant growth and development.

Photosynthetic pigments including chlorophyll $a$, chlorophyll $b$, and carotenoids were similar in all three treatments during the pre- and anthesis stages (Table 2). The exception was carotenoid concentration, which was significantly higher in the An plants compared to the NS plants during pre-anthesis. In addition, VF plants had a significantly higher carotenoid concentration compared to both NS and An plants during anthesis. These photosynthetic pigments play essential roles in capturing light energy during the light reactions of photosynthesis [23]. The concentration of these pigments can influence the photosynthetic rate through energy supply to the dark reactions [24]. Additionally, photosynthetic rate is highly influenced by $\mathrm{CO}_{2}$ supply through the stomata to the dark reaction [25]. In this study, both stomata conductance and photosynthetic pigments were similar at all treatments during the pre- and anthesis stages (Table 2, Table 3). This could be utilized to explain the similarity in $\mathrm{CO}_{2}$ assimilation among all the treatments at both stages (Table 3). However, there was a significant difference in $\mathrm{CO}_{2}$ assimilation between the two stages of growth (Table 3). In all treatments, $\mathrm{CO}_{2}$ assimilation was 
Table 1. Effect of drought on leaf water potential in tomato plants with selected fungus and virus interaction.

\begin{tabular}{ccc}
\hline & \multicolumn{3}{c}{ Stage of growth } \\
\cline { 2 - 3 } Interaction & Pre-anthesis & Anthesis \\
\cline { 2 - 3 } & \multicolumn{2}{c}{ Leaf water potential $(-\mathrm{MPa})$} \\
\hline $\mathrm{NS}{ }^{*}$ & $1.62^{* *}$ & 1.64 \\
$\mathrm{VF}$ & 1.84 & 1.60 \\
$\mathrm{An}$ & 1.79 & 1.64
\end{tabular}

${ }^{*} \mathrm{NS}$ = non-symbiotic; $\mathrm{VF}=$ virus-free; $\mathrm{An}=$ anastomosis; ${ }^{* *}$ There is no significant difference between the treatments based on the least significant difference (LSD) test $(\mathrm{P}=0.05)$.

Table 2. Effect of drought on photosynthetic pigment content in tomato plants with selected fungus and virus interaction.

\begin{tabular}{|c|c|c|c|c|c|c|}
\hline \multirow{3}{*}{ Interaction } & \multicolumn{6}{|c|}{ Stage of growth } \\
\hline & Pre-anthesis & Anthesis & Pre-anthesis & Anthesis & Pre-anthesis & Anthesis \\
\hline & \multicolumn{2}{|c|}{ Chla (mg/g FW) } & \multicolumn{2}{|c|}{ Chlb (mg/g FW) } & \multicolumn{2}{|c|}{ Caro $(\mu \mathrm{g} / \mathrm{g})$} \\
\hline $\mathrm{NS}^{*}$ & $5.094^{\mathrm{Aa}^{* *}}$ & $6.248^{\mathrm{Aa}}$ & $4.470^{\mathrm{Aa}}$ & $3.986^{\mathrm{Aa}}$ & $0.004^{\mathrm{Aa}}$ & $0.005^{\mathrm{Aa}}$ \\
\hline VF & $6.134^{\mathrm{Aa}}$ & $6.224^{\mathrm{Aa}}$ & $4.022^{\mathrm{Aa}}$ & $3.941^{\text {Aa }}$ & $0.042^{\mathrm{ABa}}$ & $0.046^{\mathrm{Ba}}$ \\
\hline An & $7.228^{\mathrm{Aa}}$ & $6.610^{\mathrm{Aa}}$ & $4.656^{\mathrm{Aa}}$ & $4.204^{\mathrm{Aa}}$ & $0.062^{\mathrm{Ba}}$ & $0.005^{\mathrm{Aa}}$ \\
\hline
\end{tabular}

"NS = non-symbiotic; VF = virus-free; An = anastomosis; ${ }^{* *}$ Means within columns followed by the same uppercase letter are not significantly different based on the least significant difference (LSD) test $(\mathrm{P}=0.05)$. Means within rows followed by the same lowercase letter of the same corresponding measurements are not significantly different based on the LSD test $(\mathrm{P}=0.05)$.

Table 3. Effect of drought on $\mathrm{CO}_{2}$ assimilation and stomata conductance in tomato plants with selected fungus and virus interaction.

\begin{tabular}{|c|c|c|c|c|}
\hline \multirow{3}{*}{ Interaction } & \multicolumn{4}{|c|}{ Stage of growth } \\
\hline & Pre-anthesis & Anthesis & Pre-anthesis & Anthesis \\
\hline & \multicolumn{2}{|c|}{$\mathrm{CO}_{2}$ assimilation $\left(\mu \mathrm{mol} \cdot \mathrm{m}^{-2} \cdot \mathrm{s}^{-1}\right)$} & \multicolumn{2}{|c|}{ Stomata conductance $\left(\mathrm{mol} \cdot \mathrm{m}^{-2} \cdot \mathrm{s}^{-1}\right)$} \\
\hline $\mathrm{NS}^{*}$ & $1.177^{\mathrm{A} \mathrm{a}^{* *}}$ & $2.318^{\mathrm{Ab}}$ & $0.708^{\mathrm{Aa}}$ & $1.741^{\mathrm{Aa}}$ \\
\hline VF & $1.033^{\mathrm{Aa}}$ & $2.013^{\mathrm{Ab}}$ & $0.322^{\mathrm{Aa}}$ & $2.722^{\mathrm{Aa}}$ \\
\hline An & $1.053^{\mathrm{Aa}}$ & $2.044^{\mathrm{Ab}}$ & $0.219^{\mathrm{Aa}}$ & $2.291^{\mathrm{Aa}}$ \\
\hline
\end{tabular}

*NS = non-symbiotic; VF = virus-free; An = anastomosis; ${ }^{* *}$ Means within columns followed by the same uppercase letter are not significantly different based on the least significant difference (LSD) test $(\mathrm{P}=0.05)$. Means within rows followed by the same lowercase letter of the same corresponding measurements are not significantly different based on the LSD test $(\mathrm{P}=0.05)$.

significantly higher during anthesis compared to pre-anthesis. Similar results were reported in various crops including sunflower (Helianthus annuus L.), sorghum (Sorghum bicolor (L.) Moench), wheat (Triticum aestivum (L.)), and chickpea (Cicer arietinum (L.)) [26]. The increase in photosynthetic rate in these four crops during anthesis was accompanied by an increase in respiration rate. This can be interpreted that the supply and demand of $\mathrm{CO}_{2}$ assimilation was the highest during anthesis.

\section{Conclusion}

Under the experimental conditions, tomato plant growth, photosynthetic pigments, water status, and photosynthetic rates were not significantly affected by the symbiotic interaction. Curvularia protuberata could have other functions than the ones examined in this research. However, drought stress was not significantly affected by the 
presence of the fungus in the system. The results under our experimental conditions did not support the findings of Rodriguez [11], which showed that C. protuberata induced drought tolerance in tomato.

\section{Acknowledgements}

This publication was made possible by the National Science Foundation grant number NSF-1354050.

\section{References}

[1] Krings, M., Taylor, T.N., Hass, H., Kerp, H., Dotzler, N. and Hermsen, E.J. (2007) Fungal Endophytes in a 400 Million-yr-Old Land Plant: Infection Pathways, Spatial Distribution and Host Responses. New Phytologist, 174, 648-665. http://dx.doi.org/10.1111/j.1469-8137.2007.02008.x

[2] Pirozynski, K.A. and Malloch, D.W. (1975) The Origin of Land Plants: A Matter of Mycotrophism. Biosystems, 6, 153-164. http://dx.doi.org/10.1016/0303-2647(75)90023-4

[3] Pilon-Smits, E.A.H., Terry, N., Sears, T., Kim, H., Zayed, A., Hwang, S., van Dun, K., Voogd, E., Verwoerd, T.C., Krutwagen, R.W.H.H. and Goddijn, O.J.M. (1998) Trehalose-Producing Transgenic Tobacco Plants Show Improved Growth Performance under Drought Stress. Journal of Plant Physiology, 152, 525-532. http://dx.doi.org/10.1016/S0176-1617(98)80273-3

[4] Vinocur, B. and Altman, A. (2005) Recent Advances in Engineering Plant Tolerance to Abiotic Stress: Achievements and Limitations. Current Opinion in Biotechnology, 16, 123-132. http://dx.doi.org/10.1016/j.copbio.2005.02.001

[5] Márquez, L.M., Redman, R.S., Rodriguez, R.J. and Roossinck, M.J. (2007) A Virus in a Fungus in a Plant: Three-Way Symbiosis Required for Thermal Tolerance. Science, 315, 513-515. http://dx.doi.org/10.1126/science.1136237

[6] Rodriguez, R.J., Henson, J., Van Volkenburgh, E., Hoy, M., Wright, L., Beckwith, F., Kim, Y. and Redman, R.S. (2008) Stress Tolerance in Plants via Habitat-Adapted Symbiosis. ISME, 2, 404-416. http://dx.doi.org/10.1038/ismej.2007.106

[7] Morsy, M.R., Oswald, J., He, J., Tang, Y. and Roossinck, M.J. (2010) Teasing Apart a Three-Way Symbiosis: Transciptome Analyses of Curvularia protuberate in Response to Viral Infection and Heat Stress. Biochemical and Biophysical Research Communications, 401, 225-230. http://dx.doi.org/10.1016/j.bbrc.2010.09.034

[8] USGCRP (2009) Global Climate Change Impacts in the United States. In: Karl, T.R., Melillo, J.M. and Peterson, T.C., Eds., United States Global Change Research Program, Cambridge University Press, New York.

[9] Food and Agriculture Organization of the United Nations (FAO) (2013) Hunger. http://www.fao.org/hunger/en/

[10] Rodriguez, R.J., Redman, R.S. and Henson, J.M. (2004) Symbiotic Lifestyle Expression by Fungal Endophytes and the Adaptation of Plants to Stress: Unraveling the Complexities of Intimacy. The Fungal Community, 683-695.

[11] Rodriguez, R.J., White Jr., J.F., Arnold, A.E. and Redman, R.S. (2009) Fungal Endophytes: Diversity and Functional Roles. New Phytologist, 182, 314-330. http://dx.doi.org/10.1111/j.1469-8137.2009.02773.x

[12] Redman, R.S., Sheehan, K.B., Stout, R.G., Rodriguez, R.J. and Henson, J.M. (2002) Thermotolerance Generated by Plant/Fungal Symbiosis. Science, 298, 1581.

[13] Penna, S. (2003) Building Stress Tolerance through Over-Producing Trehalose in Transgenic Plants. Trends in Plant Science, 8, 355-357.

[14] Crowe, J.H., Crowe, L.M. and Chapman, D. (1984) Preservation of Membranes in Anhydrobiotic Organisms: The Role of Trehalose. Science, 223, 701-703. http://dx.doi.org/10.1126/science.223.4637.701

[15] Subramanian, K.S., Santhanakrishnan, P. and Balasubramanian, P. (2006) Responses of Field Grown Tomato Plants to Arbuscular Mycorrhizal Fungal Colonization under Varying Intensities of Drought Stress. Scientia Horticulturae, 107, 245-253. http://dx.doi.org/10.1016/j.scienta.2005.07.006

[16] McDermitt, D.K., Norman, J.M., Davis, J.T., Ball, J., Arkebauer, T.J., Welles, J.M. and Roemer, S.R. (1989) CO 2 Response Curves Can Be Measured with a Field-Portable Closed-Loop Photosynthesis System. Annals of Forest Science, 46, 416s-420s. http://dx.doi.org/10.1051/forest:19890593

[17] Doong, R.L., MacDonald, G.E. and Shilling, D.G. (1993) Effect of Fluoridone on Chlorophyll, Carotenoid, and Anthocyanin Content of Hydrilla. Journal of Aquatic Plant Management, 31, 55-59.

[18] Al-Hamdani, S.H., Todd, G.W. and Francho, D.A. (1990) Response of Wheat Growth and $\mathrm{CO}_{2}$ Assimilation to Altering Root-Zone Temperature. Canadian Journal of Botany, 68, 2698-2702. http://dx.doi.org/10.1139/b90-341

[19] Chatterton, N.J., Harrison, P.A., Bennett, J.H. and Thornley, W.R. (1987) Fructan, Starch and Sucrose Concentrations in Crested Wheatgrass and Redtop as Affected by Temperature. Plant Physiology and Biochemistry (Montrouge), 25, 617-623.

[20] Dubois, M., Gilles, K.A., Hamilton, J.K., Rebers, P.A. and Smith, F. (1956) Colorimetric Method for Determination of 
Sugars and Related Substances. Analytical Chemistry, 28, 350-356. http://dx.doi.org/10.1021/ac60111a017

[21] Conlin, L.K. and Nelson, H.C.M. (2007) The Natural Osmolytetrehalose Is a Positive Regulator of the Heat-Induced Activity of Yeast Heat Shock Transcription Factor. Molecular and Cellular Biology, 27, 1505-1515. http://dx.doi.org/10.1128/MCB.01158-06

[22] Paul, M.J., Primavesi, L.F., Jhurreea, D. and Zhang, Y. (2008) Trehalose Metabolism and Signaling. Annual Review of Plant Biology, 59, 417-441. http://dx.doi.org/10.1146/annurev.arplant.59.032607.092945

[23] Smith, J.H.C. and French, C.S. (1963) The Major and Accessory Pigments in Photosynthesis. Annual Review of Plant Biology, 14, 181-224. http://dx.doi.org/10.1146/annurev.pp.14.060163.001145

[24] Inskeep, W.P. and Bloom, P.R. (1985) Extinction Coefficient of Chlorophyll $a$ and $b$ in $N, N$-Dimethylformamide and 80\% Acetone. Plant Physiology, 77, 483-485. http://dx.doi.org/10.1104/pp.77.2.483

[25] Farquhar, G.D. and Sharkey, T.D. (1982) Stomatal Conductance and Photosynthesis. Annual Review of Plant Biology, 33, 317-345. http://dx.doi.org/10.1146/annurev.pp.33.060182.001533

[26] Albrizio, R. and Steduto, P. (2003) Photosynthesis, Respiration and Conservative Carbon Use Efficiency of Four Field Grown Crops. Agricultural and Forest Meteorology, 116, 19-36. http://dx.doi.org/10.1016/S0168-1923(02)00252-6 